This item was submitted to Loughborough's Research Repository by the author.

Items in Figshare are protected by copyright, with all rights reserved, unless otherwise indicated.

\title{
Interface pressure data and the prediction of driver discomfort in road trials
}

PLEASE CITE THE PUBLISHED VERSION

http://dx.doi.org/10.1016/S0003-6870(03)00009-7

\section{PUBLISHER}

(c) Elsevier

VERSION

AM (Accepted Manuscript)

\section{PUBLISHER STATEMENT}

This work is made available according to the conditions of the Creative Commons Attribution-NonCommercialNoDerivatives 4.0 International (CC BY-NC-ND 4.0) licence. Full details of this licence are available at: https://creativecommons.org/licenses/by-nc-nd/4.0/

\section{LICENCE}

CC BY-NC-ND 4.0

\section{REPOSITORY RECORD}

Porter, J. Mark, Diane E. Gyi, and Hilary A. Tait. 2019. "Interface Pressure Data and the Prediction of Driver Discomfort in Road Trials". figshare. https://hdl.handle.net/2134/15732. 
Porter JM, Gyi DE and Tait HA (2003). Interface pressure and the prediction of driver discomfort in road trails. Applied Ergonomics 34, 207-214.

\title{
Interface pressure data and the prediction of driver discomfort in road trials
}

\author{
J. Mark Porter, Diane E. Gyi*, Hilary A. Tait \\ Department of Design and Technology, Loughborough University, Leicestershire, LE11 \\ 3TU, $U K$
}

Telephone: +44(0) 1509223026

Email: d.e.gyi@lboro.ac.uk 


\begin{abstract}
An objective measure that will predict discomfort reliably, and which can be used at an early stage in the development of a vehicle and its seating, would have the potential to reduce the prevalence of musculoskeletal problems associated with driving. This paper reports on an extended road trial study to further investigate the potential value of pressure distribution data in the prediction of reported discomfort. Road trial data were collected from three cars and then interface pressure data were recorded for each of the three seats. Clear differences were identified between the cars with respect to reports of discomfort. However, no clear relationship was found between interface pressure data and reported discomfort.
\end{abstract}

Keywords: discomfort, driving, interface pressure measurement 


\section{Introduction}

The Vehicle Ergonomics Group (VEG) has evaluated over 100 vehicles since 1981 and has established methods of collecting mainly subjective data for evaluating the driving workstation during extended road trials. Whilst these data are of high quality, it is a lengthy process, sometimes taking several months to complete and it is often carried out at a late stage in the vehicle's development when the car is a pre-production prototype or already in production (Porter, 1995). An accurate method for predicting body area discomfort, and consequently assessing the quality of the seat and driving package, would have a major advantage of providing rapid information which could be used early on in the design process.

There is potential for seated pressure distribution to be used as a predictor of discomfort. For example, the tissues covering the ischial tuberosities can be subjected to extremely high pressures during sitting that are sufficient to reduce blood circulation through the capillaries. If there is no readjustment of body position, then metabolite build up and the symptoms of aches, pain, discomfort and numbness occur. It then seems logical in any seating design that areas of high pressure should be minimised and pressure optimally distributed across the sitting region. Car manufacturers are already interested in using interface pressure measurement as a technique for predicting discomfort (e.g. Lee and Ferraiuolo, 1993; Gross et al, 1994; Thakurta et al, 1995).

The literature attempting to correlate discomfort with interface pressure data is not extensive, is of limited value and is discussed in a previous paper (Gyi and Porter, 1999). The conclusions are generally contradictory and often based on short duration trials of 5, 10 or 15 minutes (e.g. Gross et al, 1994; Lee and Ferraiuolo, 1993; Shen and Galer, 1993), such that further exploration of the technique is clearly required. Earlier research on interface pressure measurement carried out by the authors (Gyi et al, 1998; Gyi and Porter, 1999) has not shown a clear relationship between discomfort and interface pressure data, based on data from 2.5 hour laboratory 'driving trials' controlling for either seat design or posture.

This paper describes an extended road-trial study to further investigate the potential value of pressure distribution data in the prediction of reported discomfort. Three cars were used in the road trials study (one prototype and two production models from competitor manufacturers). 


\section{Method}

\subsection{Participant selection}

A sample of 18 drivers, 8 male and 10 females, was carefully selected from the British public to include a wide range of body sizes (Figure 1). Individuals were chosen initially by height and then the sample was refined to produce a good range across percentiles for both males and females in the other six anthropometric variables measured. Driving licenses were checked and prospective subjects took a 15 minute 'test drive' accompanied by the experimenter. Drivers who were nervous or experienced any problems were excluded. The mean age of the selected sample was 40 years (SD 12). 
Figure 1. Anthropometric data for males and females. Percentile value is for British adults (Pheasant, 1990).

Males

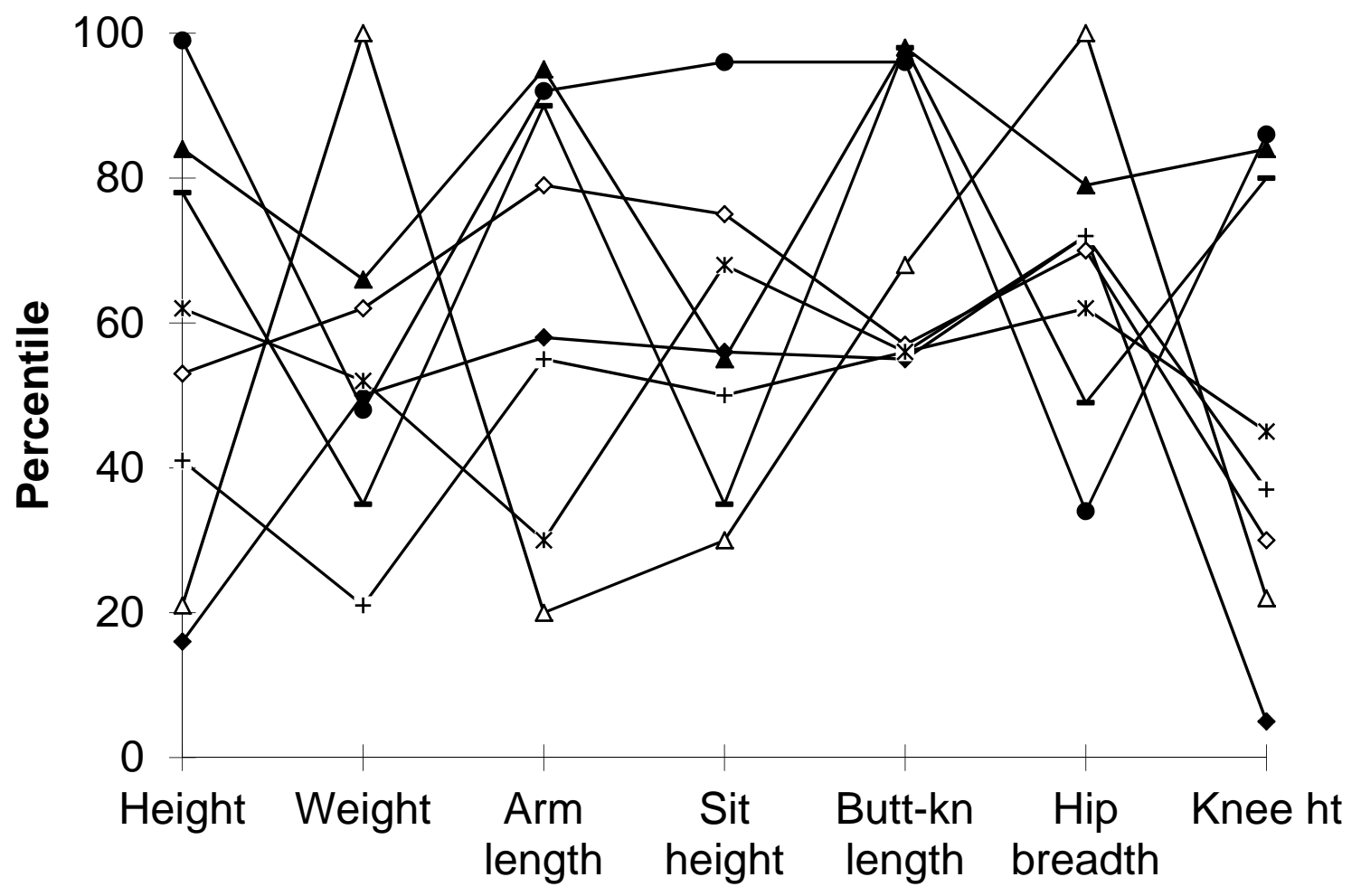

Females

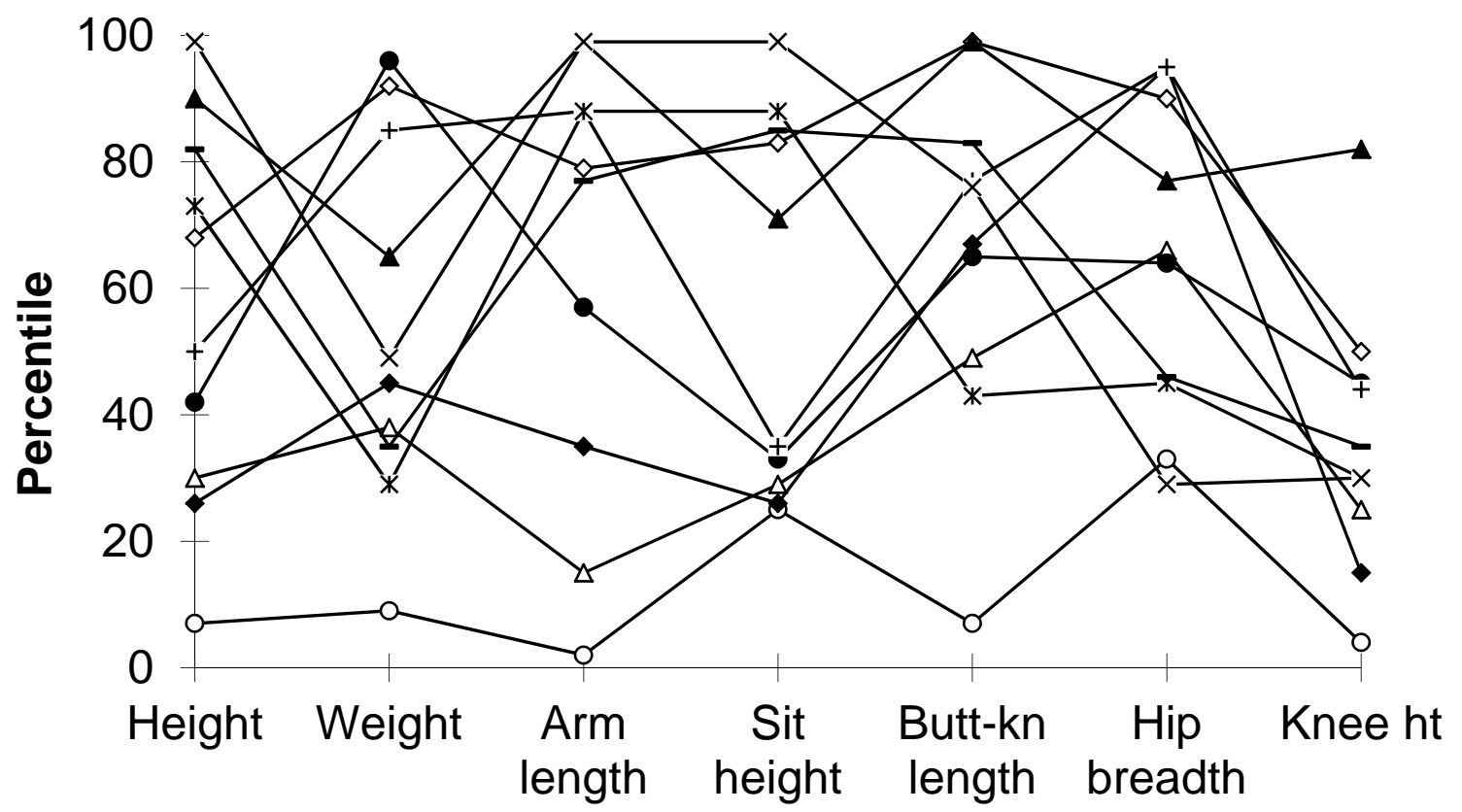




\subsection{Road Trials}

The road trials involved three left-hand drive cars from the same class (Cars A, B and C). Each participant drove all three cars on different days and, whenever possible, on the same day of the week, at the same time of day, with the same experimenter and in a balanced order. This standardisation helped to control for the effects of extraneous variables, which can influence subjective discomfort data (e.g. previous activity, road traffic, fatigue etc.). In addition, participants were requested to keep their activities as similar as possible prior to driving on each the trial days. Each road trial took approximately 2.5 hours and included 15 minutes of simulated showroom conditions, followed by approximately 120 minutes of driving over the standard 60 mile test route involving different road conditions (open roads, towns and motorways), with 15 minutes of debriefing at the end. During each road trial, the participants completed a seat feature checklist (similar in nature to that used by Shackel et al, 1969) and a 20 body part comfort/discomfort chart (see Figure 3 for a list of body areas; see also Gyi \& Porter, 1999, for format), The chart incorporated a 7 point scale (1 very comfortable; 2 comfortable; 3 fairly comfortable; 4 neutral; 5 slightly uncomfortable; 6 uncomfortable; 7 very uncomfortable) and was administered after approximately 15, 45, 75, 105 and 135 minutes of driving whilst the car was stationary in convenient lay-bys. Such a rating scale ( 5 or 7 point) has been used extensively by the first author for over 20 years. It is quick and easy to use with no training required (drivers are simply asked to use the scale in a consistent manner from trial to trial). Analysis can be conducted using the entire scale (e.g. Freidman’s two-way ANOVA) or by collapsing the scale to 2 points: 'no discomfort' (scale points 1-4) and 'discomfort' (scale points 5-7). In the latter case, Cochran's Q Test can be used for analysis. Using the whole scale for analysis may identify differences between seats, even if the seats are all generally good or poor. The dichotomous scale, whilst crude, often reveals a clearer picture as it relates to the percentage of drivers reporting discomfort in each seat. It is recommended that both complementary analyses are conducted. Comparative studies for cars from the same market sector have revealed problems with prototype seats that have been subsequently rectified following design interventions and re-testing (see Porter 1995). Participants also completed further questionnaires on aspects of the car such as the displays and controls, seat design and adjustment, seat belts and mirrors. The positions of the seat and controls were recorded at the end of each trial. 


\subsection{The collection of interface pressure and posture data}

Interface pressure readings were recorded using the Pliance system, a capacitive method developed by the German company @Novel gmbh. This system consists of a flexible and elastic measuring mat, a multi-channel analyser, a calibration device and a software package for personal computers. According to the manufacturers once calibrated, the system could be expected to take accurate readings within $+/-5 \%$ for six months. Two of the measuring mats were required for this study, each $2.6 \mathrm{~mm}$ thick, with a total sensor area of 506 x 506 mm, containing 32 x 32 sensors (1024 sensors) arranged in a matrix configuration. The 2000/B-5 Pliance analyser for two mats was used which has the capacity of reading 5000 sensors per second.

It was considered that the pressure sensing mat would have an effect on subjectcar seat interface (and consequently upon any discomfort experienced) if used throughout the road trials. For example, as the mat was non-absorbent it would have been expected to increase both skin temperature and moisture levels. In addition, the mat may have encouraged the driver to slide forwards on the seat with associated changes in posture and pressure distribution. For such reasons, all subjects returned for a one hour experimental session following the road trials to measure their interface pressure in each of the three cars; the seat and controls being set-up individually as in each road trial. They were requested to wear clothes suitable for driving but without heavy seams, buttons or pockets in order that there was minimal effect on the pressure readings. Subjects adopted their usual driving position for this measurement (i.e. semidepressing the accelerator, hands on the steering wheel and looking ahead), held for 30 seconds. The car was stationary and was parked in a large garage with a level floor.

Driving posture was measured using a goniometer with subjects adopting their normal driving position in each of the left-hand drive cars. Joint markers were positioned on anatomical landmarks on the left side of the body (7th cervical vertebra, acromium, lateral epicondyle, ulnar styloid, greater trochanter, lateral condyle and lateral malleolus) to aid measurement through clothing. The average of three readings of each angle, for each car was recorded. Postural angles were defined as follows, adapted from Grandjean et al (1983), Bridger (1988) and Bhatnager et al (1985):-

(i) Ankle angle: The angle between a line from the lateral condyle to the lateral malleolus and a line parallel with the foot. 
(ii) Arm flexion: The angle between the vertical and a line from the acromium to the lateral epicondyle.

(iii) Elbow angle: The angle between a line from the acromium to the lateral epicondyle and a line from the ulnar styloid to the lateral epicondyle.

(iv) Knee angle: The angle between a line from the greater trochanter to the lateral condyle and a line from the lateral malleolus and the lateral condyle.

(v) Neck inclination: The angle between the vertical and a line from the 7th cervical vertebrae to the auditory canal.

(vi) Thigh from horizontal: The angle between the horizontal and a line from the lateral condyle to the greater trochanter

(vii) Thigh from vertical: The angle between the vertical and a line from the acromium to the greater trochanter.

(viii) Trunk-thigh angle: The angle between a line from the acromium to the greater trochanter and a line from the lateral condyle to the greater trochanter.

\subsection{Data analysis}

The analyses are presented for males and females together as one sample for two main reasons:-

(1) Extensive data exploration found no consistent, significant differences between males and females in either the comfort or interface pressure data, for the three cars.

(2) It is unlikely that car seats will be designed to reflect gender differences. The mean (Pmean) and maximum (Pmax) interface pressure variables were extracted for each of the whole seat, the left and right ischial tuberosities (IT), left and right thighs, upper back and lower back. The method employed was based on previous work (Gyi and Porter 1999). The mean value (over the 30 seconds) for each sensor was calculated using the Pliance software and displayed as a point on the pressure map. The pressure variables were calculated by consideration of the whole pressure map; the readings of 20 sensors (area $5000 \mathrm{~mm}^{2}$ ) were used to define the area of contact under each IT and 29 sensors (area $7250 \mathrm{~mm}^{2}$ ) to define a rectangular area of contact under the centre of each thigh. The back pressure variables were calculated from the sensors identified as the contact area above the lower tip of the scapula (upper back) and the area below this (mid and lower back). The ITs were typically clearly defined on the 
pressure plots and it was easy to select 20 sensors to define these areas for each subject/seat pairing. The location of the selected thigh sensors varied depending upon the length of each subject's thigh. The IT and thigh sensors did not overlap.

In order to investigate the relationship between interface pressure and discomfort, three discomfort variables (from the seven point rating scale) were calculated for each of the buttocks, thighs and low back. These were: mean rating over the trial, rating after 135 minutes and total minutes of reported discomfort. The latter measure was calculated by assigning 30 minutes of discomfort for each report of discomfort (i.e. a rating of 5, 6 or 7). The total number of minutes of reported discomfort for a specific body area was calculated from the 5 assessments, the maximum number being 150 minutes.

Parametric and nonparametric measures of linear association and sample differences were employed. The extensive data exploration and analyses were performed using SPSS for Macintosh Computers (Norusis, 1990).

\section{Results}

\subsection{Reported discomfort}

Friedman's two-way Analysis of Variance (ANOVA) by ranks was calculated from the road trial discomfort data at each of the five time periods. Cochran's Q test was applied to the same data converted to dichotomous form (discomfort / no discomfort).

Discomfort was clearly observed to increase over time, for example, the back, buttocks and thighs as illustrated in Figure 2. Table 1 shows the body areas with significant differences in discomfort between the cars. Car $\mathrm{C}$ received the highest percentage of complaints of discomfort after 135 minutes in 18 out of the 20 body areas. High levels of low back discomfort were evident after just 15 minutes in Car C (Figure 2). Car C also had the greatest number of minutes of reported discomfort over the 2.5 hours in 12 out of the 20 body areas evaluated (Figure 3). 
Table 1. Significant differences, and those approaching significance, in the reported discomfort between the three cars over time $(n=18)$.

\begin{tabular}{|c|c|c|c|c|c|c|}
\hline Body area & $\begin{array}{c}\text { Number of } \\
\text { minutes }\end{array}$ & $\begin{array}{c}\text { Car A } \\
\%\end{array}$ & $\begin{array}{c}\text { Car B } \\
\%\end{array}$ & $\begin{array}{c}\text { Car C } \\
\%\end{array}$ & Cochran's Q & Friedman \\
\hline \multirow[t]{4}{*}{ Left buttock } & 45 & 0 & 11 & 33 & $* *$ & ns \\
\hline & 75 & 17 & 11 & 39 & $*$ & $*$ \\
\hline & 105 & 6 & 22 & 33 & (a) & ns \\
\hline & 135 & 22 & 17 & 44 & ns & $*$ \\
\hline \multirow[t]{4}{*}{ Right buttock } & 45 & 0 & 0 & 33 & $* *$ & ns \\
\hline & 75 & 17 & 11 & 44 & $*$ & $* *$ \\
\hline & 105 & 11 & 22 & 44 & $*$ & $*$ \\
\hline & 135 & 22 & 17 & 50 & * & $* *$ \\
\hline \multirow[t]{2}{*}{ Left thigh } & 45 & 6 & 11 & 22 & (a) & ns \\
\hline & 135 & 11 & 17 & 44 & $*$ & ns \\
\hline \multirow[t]{3}{*}{ Right thigh } & 45 & 11 & 6 & 22 & (a) & ns \\
\hline & 105 & 17 & 11 & 33 & $*$ & (a) \\
\hline & 135 & 17 & 22 & 44 & * & ns \\
\hline \multirow[t]{5}{*}{ Low back } & 15 & 0 & 6 & 28 & $* *$ & ns \\
\hline & 45 & 0 & 6 & 28 & $* *$ & ns \\
\hline & 75 & 6 & 11 & 33 & $* *$ & $*$ \\
\hline & 105 & 17 & 11 & 50 & * & $* * *$ \\
\hline & 135 & 28 & 17 & 50 & (a) & $* *$ \\
\hline
\end{tabular}




$\begin{array}{lcccccc}\text { Mid/low back } & 15 & 0 & 3 & 14 & * * & \text { ns } \\ & 45 & 0 & 3 & 19 & * * & * \\ & 75 & 6 & 11 & 28 & * * & * * \\ & 105 & 14 & 14 & 36 & (a) & * * * \\ & 135 & 25 & 11 & 47 & * & * * * \\ \text { Upper back } & 105 & 17 & 0 & 28 & * & \text { ns } \\ & 135 & 17 & 11 & 39 & \text { (a) } & \text { ns }\end{array}$

ns = not significant, $(a)=0.1>p>0.05, *=p<0.05, * *=p<0.01, * * *=p<0.001$ 
Figure 2. Percentage of drivers ( $n=18)$ reporting discomfort at 15, 45, 75, 105 and 135 min of simulated driving.

Upper back

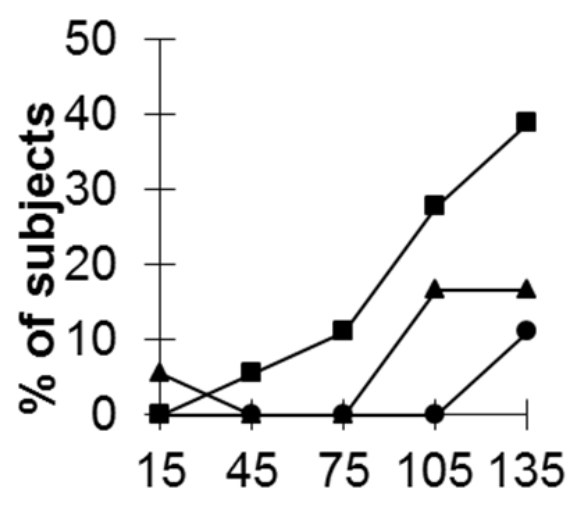

Left buttock

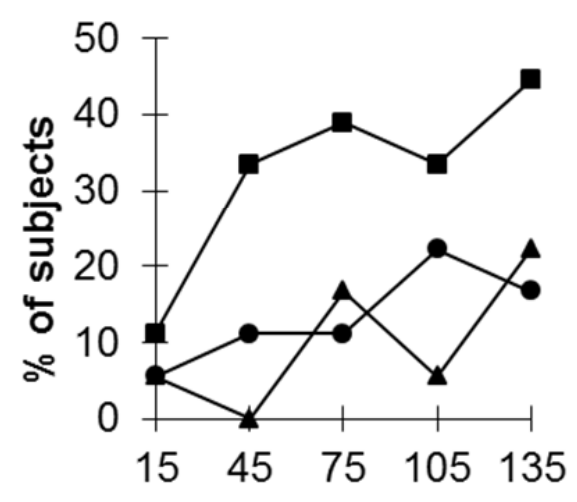

Left thigh

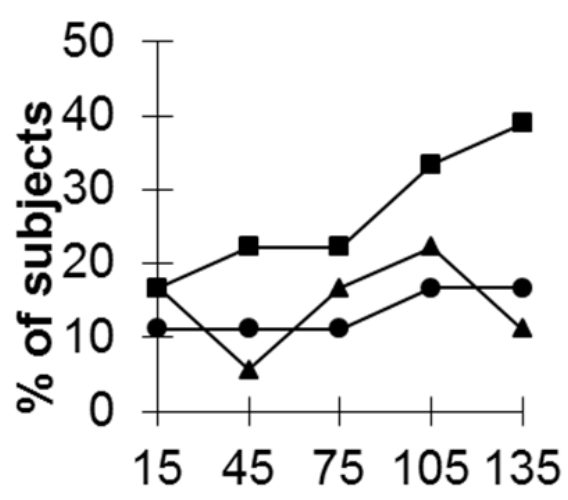

Lower back

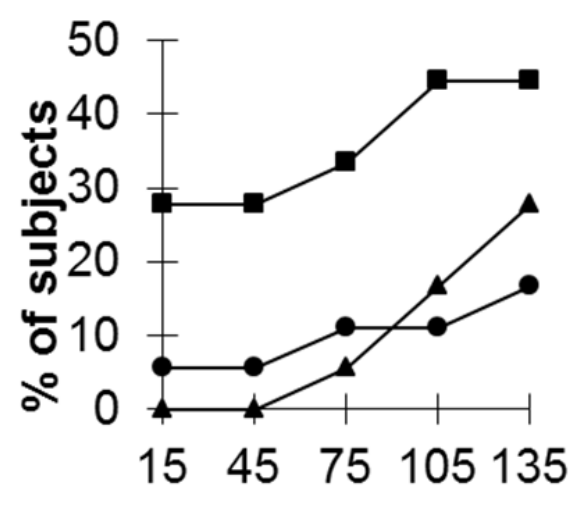

Right buttock

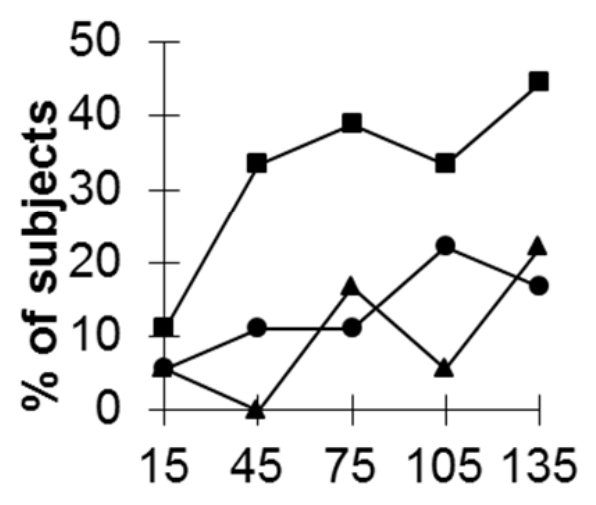

Right thigh

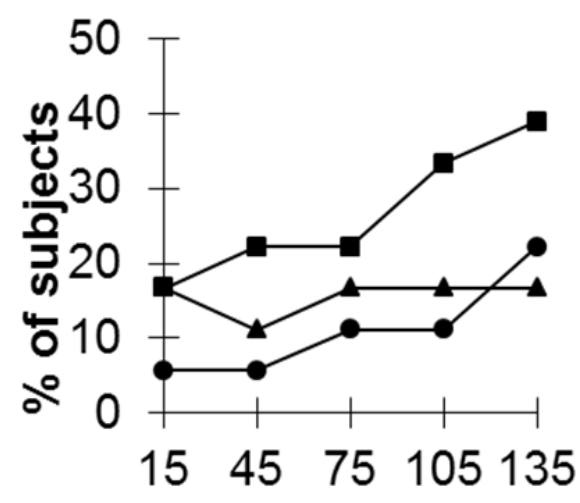


Figure 3. Driver's mean number of minutes of reported discomfort.

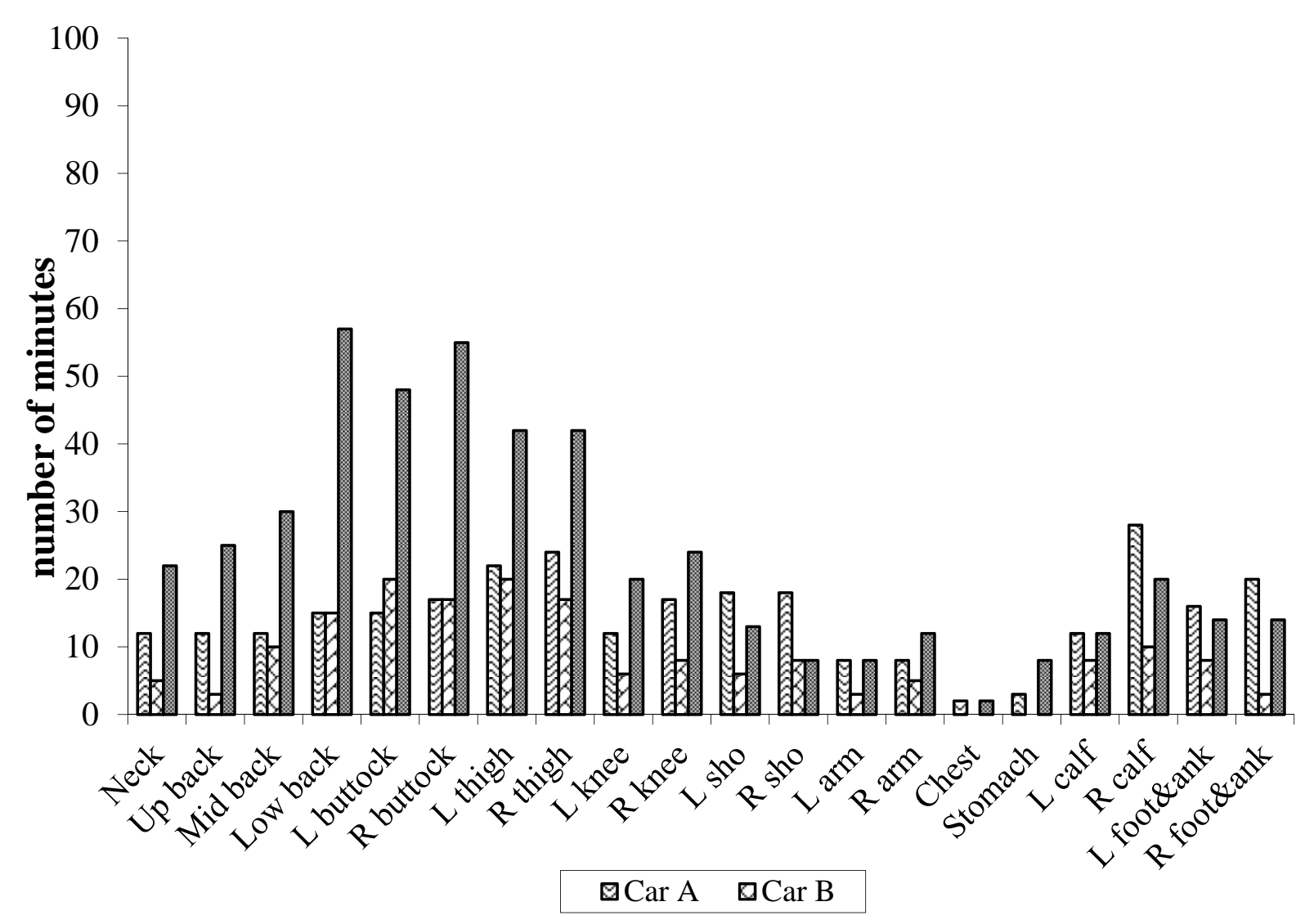


A comparison of the mean number of minutes of reported discomfort in Car C with the durations for Cars A and B, clearly show that Car C was appreciably more uncomfortable. For example, in the lower back: 57 minutes versus 15 minutes for Cars B and C; in the right buttock: 55 minutes versus 17 minutes for Cars B and C; and in the right thigh: 44 minutes versus 24 and 17 minutes for Cars A and B respectively. The extent of these differences in reported discomfort has considerable design relevance and it would be essential that any predictive method for assessing discomfort would be able to identify Car C as being markedly worse that the other two cars in this respect.

\subsection{Posture}

Using one-way ANOVA for repeated measures, significant differences were found between the cars for foot-calf angle, arm flexion, elbow angle, knee angle and thigh angle from the horizontal (Table 2). Drivers in Car C were significantly more extended in the knees (3-5 degrees) and ankles (7-11 degrees), and more flexed in the arms (5-9 degrees) and elbows (10-12 degrees). Neck and trunk inclination and trunk-thigh angles were very similar between cars. It should be noted that the seat height in Car C was the lowest of the three cars, which helps to explain the leg posture.

\subsection{Interface pressure data}

Table 3 presents the interface pressure data for the three cars and significant differences using one-way ANOVA for repeated measures. Pressure values are shown in mmHg (1 $\mathrm{mmHg}=133.3 \mathrm{~Pa})$. Car B had significantly lower IT pressure values, for example a Pmean of $36 \mathrm{mmHg}$ in the left IT compared with $44 \mathrm{mmHg}$ (Cars A and C). Thigh pressure values in Car B were the highest for example, a Pmean of $18 \mathrm{mmHg}$ in the left thigh compared with $12 \mathrm{mmHg}$ (Car A) and $16 \mathrm{mmHg}$ (Car C). There were no significant differences between the cars for the back pressure values. 
Table 2. Observed postural angles for the three cars $(n=18)$.

\begin{tabular}{lcccc}
\hline Measurement (degrees) & Car A & Car B & Car C & Significance \\
& Mean (SD) & Mean (SD) & Mean (SD) & \\
\hline Ankle angle & $101(8.3)$ & $105(6.9)$ & $112(10.1)$ & $* * * *$ \\
Arm flexion & $48(11.3)$ & $52(12.2)$ & $43(11.2)$ & $* * * *$ \\
Elbow angle & $114(18.8)$ & $116(20.6)$ & $104(16.5)$ & $* * * *$ \\
Knee angle & $112(11.6)$ & $114(8.7)$ & $117(9.3)$ & $*$ \\
Neck inclination & $55(9.7)$ & $55(10.4)$ & $54(10.3)$ & ns \\
Thigh from horizontal & $16(5.1)$ & $14(3.8)$ & $16(5.3)$ & $*$ \\
Trunk from vertical & $20(5.7)$ & $20(5.8)$ & $20(4.6)$ & ns \\
Trunk-thigh angle & $94(8.3)$ & $95(7.9)$ & $92(6)$ & ns \\
\hline ns $=$ not significant, (a) $=0.1>\mathrm{p}>0.05, *=\mathrm{p}<0.05, * *=\mathrm{p}<0.01, * * *=\mathrm{p}<0.001$, \\
$* * * *=\mathrm{p}<0.0001$
\end{tabular}

Table 4. Significant Spearman's rank-order correlation coefficients $(\mathrm{p}<0.05)$ between the comfort and interface pressure variables.

\begin{tabular}{|c|c|c|c|}
\hline \multirow{2}{*}{$\begin{array}{c}\text { Measurement } \\
\text { (mmHg) }\end{array}$} & \multicolumn{3}{|c|}{ Corresponding comfort variable $(\mathrm{r}=)$} \\
\hline & Car A & Car B & Car C \\
\hline \multicolumn{4}{|l|}{ Right IT } \\
\hline Pmean & & 15 mins $(-.49)$ & \\
\hline \multicolumn{4}{|l|}{ Right thigh } \\
\hline Pmean & mean rating $(.52)$ & & \\
\hline \multirow[t]{2}{*}{ Pmax } & & 15 mins $(.57)$ & \\
\hline & & mean rating $(.47)$ & \\
\hline \multicolumn{4}{|l|}{ Upper back } \\
\hline \multirow[t]{2}{*}{ Pmean } & & 135 mins $(.61)$ & \\
\hline & & mean rating $(.58)$ & \\
\hline
\end{tabular}


Table 3. Interface pressure data for the three cars $(n=18)$.

\begin{tabular}{|c|c|c|c|c|}
\hline Measurement (mmHg) & $\begin{array}{c}\text { Car A } \\
\text { Mean (SD) }\end{array}$ & $\begin{array}{c}\text { Car B } \\
\text { Mean (SD) }\end{array}$ & $\begin{array}{c}\text { Car C } \\
\text { Mean (SD) }\end{array}$ & Significance \\
\hline \multicolumn{5}{|l|}{ Left IT } \\
\hline Pmean & $44(11.7)$ & $36(7.1)$ & $44(6.7)$ & $* * *$ \\
\hline Pmax & $57(17.1)$ & $47(12.8)$ & $60(12.5)$ & $*$ \\
\hline \multicolumn{5}{|l|}{ Right IT } \\
\hline Pmean & 38 (9.1) & 35 (5.3) & 37 (8.7) & ns \\
\hline Pmax & $53(14.2)$ & 48 (8.6) & $52(10.7)$ & ns \\
\hline \multicolumn{5}{|l|}{ Left thigh } \\
\hline Pmean & $12(6.6)$ & $18(5.7)$ & $16(6.8)$ & $* * *$ \\
\hline Pmax & $22(9.4)$ & 25 (6.3) & $24(7.1)$ & ns \\
\hline \multicolumn{5}{|l|}{ Right thigh } \\
\hline Pmean & $13(6.3)$ & 17 (6.5) & $14(5.1)$ & $*$ \\
\hline Pmax & $22(8.7)$ & $24(7.8)$ & $23(7.7)$ & ns \\
\hline \multicolumn{5}{|l|}{ Low \& mid back } \\
\hline Pmean & $11(4.6)$ & $12(3.4)$ & $11(4.6)$ & ns \\
\hline Pmax & 30 (11.9) & 33 (12.5) & 34 (15.9) & ns \\
\hline \multicolumn{5}{|l|}{ Upper back } \\
\hline Pmean & $10(4.4)$ & $9(5.2)$ & $9(4.1)$ & ns \\
\hline Pmax & 27 (8.7) & $27(14.4)$ & $28(9.5)$ & ns \\
\hline
\end{tabular}




\subsection{Correlations between interface pressure and comfort}

Nonparametric correlation coefficients were calculated between the discomfort variables for each of the buttocks, thighs and back (at 15 minutes, 135 minutes, mean rating over the trial and total minutes of reported discomfort) and the corresponding interface pressure variables (mean and maximum) - see Table 4. Five, of the six in total, significant $(\mathrm{p}<0.05)$ Spearman's rank order correlation coefficients were found within the data for Car B. These were Pmean under the right IT and the right buttock comfort rating at 15 minutes ( $\mathrm{r}=-0.49$ ); Pmax under the right thigh and the right thigh comfort rating at 15 minutes ( $r=0.57)$ and the mean rating $(r=0.47)$; and Pmean in the upper back and the upper back comfort rating at 135 minutes ( $\mathrm{r}=0.61)$ and mean rating $(\mathrm{r}=0.58)$. The only significant correlation for Car A was Pmean under the right thigh and the thigh mean rating $(\mathrm{r}=0.52)$. No significant correlations were found within the data for Car C. A series of scattergraphs were also created to aid the identification of non-linear relationships but no consistent picture emerged.

\section{Discussion}

There was strong agreement amongst the subjects that Car $\mathrm{C}$ was the most uncomfortable of the three cars when considering buttock, thigh and back discomfort. Figures 2 and 3 clearly expose this car as a potential 'health hazard' given the level of reported discomfort in comparison to the other two cars. Car $\mathrm{C}$ was not the prototype car, but had been in production for several years. It would be of considerable interest to interview long term owners of these cars to assess whether owners of Car C actually experienced a higher prevalence of chronic musculoskeletal problems. Unfortunately, this could not be undertaken.

If interface pressure is to be successfully used by seat manufacturers as a primary means of predicting occupant discomfort, then this method must be capable of identifying Car C as providing unacceptably high levels of discomfort. However, only four significant differences were found between the vehicles for the interface pressure data (Table 3), despite the very substantial discomfort differences. The IT pressures recorded in Cars A and C were very similar with means of 41.0 and $40.5 \mathrm{mmHg}$ and maxima of 55.0 and $56.0 \mathrm{mmHg}$, respectively (avaraged across left and right ITs). However, discomfort in the buttocks showed extensive differences with $22 \%$ of drivers in Car A reporting discomfort compared to 50\% in Car B after 135 minutes of driving. 
Similarly, the mean number of minutes of reported discomfort in the right buttock was only 17 minutes compared to 55 minutes in Car C.

Thigh pressures recorded in Car C were inside the range recorded in Cars A and B even though $49 \%$ of drivers in Car $\mathrm{C}$ reported thigh discomfort compared to only $17 \%$ and 22\% in Cars A and B. Similarly, the mean number of minutes of reported discomfort in the right thigh was 44 minutes in Car C compared to 24 and 17 minutes in Cars A and B.

No significant pressure differences were observed for the back areas even though $50 \%$ of drivers in Car C reported low back discomfort at 135 minutes compared to $28 \%$ and $17 \%$ in Cars A and B. Similarly, the mean number of minutes of reported discomfort in the low back was 57 minutes in Car C compared to 15 minutes for Cars A and $\mathrm{B}$.

Furthermore, out of 240 Spearman's rank correlation coefficients calculated between buttock, thigh and back pressure and comfort variables, there were only six significant correlations. None of these were in Car C, the vehicle with the most reported discomfort. It was thus deduced that no clear and consistent relationship existed between subjective ratings of discomfort and the interface pressure readings selected for these cars.

Arm flexion, elbow, knee and ankle angles for all the cars were generally within the ranges recommended for comfort by Rebiffe (1969). Recent work by Porter and Gyi (1998) supports this with the exception of ankle angle in Car C being greater than recommended. Subjects in Car C also had significantly larger knee angles than other vehicles and provided the most complaints of knee discomfort. It was observed that the subjects' knees were inclined to press against the centre console in Car $\mathrm{C}$ that could have contributed to some of these complaints. Subjects in Car C also had a more flexed upper limb posture, although reported arm and shoulder discomfort were not significantly different between vehicles.

The lack of a simple relationship between pressure values and reported discomfort during an extended drive highlights a real concern that the quality of seat design will not improve if such an objective predictive technology is going to be used in car seat design without validation. The authors do see practical use for interface pressure measurement in exploring, at an early development stage, the effect of changing seat design variables upon the resulting pressure distribution for a representative sample of occupants. Such variables could include a change in foam density or thickness, the use 
of different covering materials and the location of stitching as well as modification to the adjustability of the seat. The objective pressure data could be used to understand the influence of the above changes in seat design upon issues such as seat hardness and support. However, the gold standard for assessing occupant comfort/discomfort still requires subjective data from road trials.

This present study recorded the 'static' interface pressure data with the vehicle stationary for technical and safety reasons. As car seat manufacturers are increasingly using static data in the development of their prototype seats, there is a clear need to determine whether such data can usefully predict discomfort. The results of this study do not support such use. It can be argued that static data are unlikely to predict driver discomfort as this is a dynamic phenomenon. For example, upon the onset of discomfort in the right thigh the driver may change posture (consciously or subconsciously) to place more pressure under the left thigh. Future research should examine whether detailed analyses of changes in driving posture and 'dynamic' interface pressures during the road trials can provide a more consistent relationship with reported discomfort. In the measurement of dynamic interface pressure over time, it is particularly important that: the pressure sensors are unobtrusive at the seat/person interface; the system is practical to use when driving; the performance of the sensors are not adversely affected by the seated subject over a long drive; and that the large amount of data collected are easily collated and quantified in a suitable output format (Gyi et al, 1998). Also, factors such as poor breathability, and the coefficient of friction of any pressure-sensing mat are likely to directly influence seating comfort.

Postural fixity is one of the major problems facing the design of car seating, particularly for the driver who is fixed in position by the pedals, steering wheel, seat belt, lateral support, and the need to look directly ahead for most of the journey. The increasing acceptance of dynamic seating in the office suggests that future cars should incorporate seating designs that permit frequent changes in posture and interface pressure distribution. The constraints of safe driving will mean that any changes to the shape of the seat or its adjustment will need to be carefully controlled and limited in their range. The design of an integrated package involving changes to the nature of the seat interface (e.g. hardness, support, massage effect) and the concerted adjustment of the seat and primary controls to provide a variety of postures to suit each individual driver's body size, build and personal preferences, may confer significant benefits to the high mileage driver. 


\section{Conclusions}

This research has confirmed that the simple quantification of static seat interface pressure data from a variety of individuals, with the assumption that high (or low) pressure values are predictors of reported discomfort during an extended drive, is unsatisfactory. It thereby supports the conclusion of the previously reported laboratory based study (Gyi and Porter, 1999).

As driver discomfort is a dynamic phenomenon, it is recommended that dynamic data are captured regarding changes over time in driving posture and interface pressures. It is important that the recording equipment does not, in itself, cause the driver to modify his or her posture or to influence discomfort directly. Further research is necessary to identify if there are any consistent relationships between these dynamic measures and the reported discomfort during the trial. Until then, the gold standard for determining driver discomfort and the comparative evaluation of seat comfort will remain with the use of carefully controlled subjective data.

\section{Acknowledgements}

The authors would like to acknowledge the Brite-Euram European Initiative (Project 5547) for funding this research. The authors would also like to thank Novelgmbh for the loan of the Pliance system for the purpose of this work.

\section{References}

Bhatnager, V., Drury, C.G., Schiro, S.G., 1985. Posture, postural discomfort and performance. Human Factors 27 (2), 189-199.

Bridger, R.S., 1998. Postural adaptions to a sloping chair and worksurface. Human Factors 30 (2), 237-247.

Grandjean, E., Hunting, W., Pidermann, M., 1983. VDT workstation design: preferred settings and their effects. Human Factors 25, 161-175.

Gross, C.M., Goonetilleke, R.S., Menon, K.K., Banaag, J.C.N., Nair, C.M., 1994. In: Lueder R., Noro, K. (Eds.), Hard Facts about Soft Machines: The Ergonomics of Seating, London: Taylor \& Francis, pp. 231-253. 
Gyi, D.E., Porter, J.M., Robertson, N.K.B., 1998. Seat pressure measurement technologies: considerations for their evaluation. Applied Ergonomics 27 (2), 85-91.

Gyi, D.E., Porter J.M., 1999. Interface pressure and the prediction of car seat discomfort. Applied Ergonomics 30 (2), 99-107.

Lee, J., Ferraiuolo, P., 1993. Seat comfort, S.A.E. Technical Paper No. 930105.

Pheasant, S.T., 1990. Anthropometrics - an introduction. London: British Standards Institute.

Porter, J.M., 1995, Keynote paper: The ergonomics development of the Fiat PuntoEuropean Car of the Year. In A. de Moraes, S. Marino (Eds), Proceedings of the International Ergonomics Association World Conference Rio de Janeiro, 1995, pp. 73-76.

Porter, J.M., Gyi, D.E., 1998. Exploring the optimum posture for driving comfort. International Journal of Vehicle Design 19 (3), 255-266.

Rebiffe, R., 1969. The driving seat: Its adaption to functional and anthropometric requirements. In: Proceedings of a Symposium on Sitting Posture, pp.132-147.

Shackel, B., Chidsey, K.D., Shipley, P., 1969. The assessment of chair comfort, Ergonomics 12 (2), 269-306.

Shen, W., Galer, I.A.R., 1993. Development of a pressure related assessment model of seating comfort. Proceedings of the Human Factors and Ergonomics Society Society 37thh Annual Meeting, October 1999, (2), pp. 831-835.

Thakurta, K., Koester, D., Bush, N., Bachle, S., 1995. Evaluating short and long term seating comfort, S.A.E. Technical Paper No. 950144. 